\title{
Horizontal push out tests on a steel-yielding demountable shear connector
}

\author{
E. Feidaki ${ }^{a}$, G. Vasdravellis ${ }^{\text {a* }}$ \\ ${ }^{a}$ Heriot-Watt University, Institute for Infrastructure and Environment, UK \\ *corresponding author, e-mail address: G.Vasdravellis@hw.ac.uk
}

\begin{abstract}
The most common type of a steel concrete composite beam is the one using conventional welded headed studs to connect the top flange of a steel beam to the concrete slab. However, the monolithic structure between the headed studs and the concrete slab prevents the deconstruction of the beam. More sustainable solutions in construction can be achieved by developing demountable connections which allow for fully deconstruction and reuse of all structural systems.

This paper presents a novel demountable shear connector for use in steel concrete composite beams in conjunction with precast hollow core slab units. The demountable connection proposed has the advantages of minimal use of in situ concrete required only in specific regions, increased ductility due to the unique shape of the shear connector and since it is not embedded in in situ concrete, it facilitates the deconstruction procedure. Ten horizontal push out tests aiming at investigating the structural performance of the demountable shear connector were carried out. The strength of the connection is predicted using simple mechanics based on plastic beam analysis. The experimental results showed that the proposed demountable shear connector can achieve increased strength depending on the geometric characteristics of the connector, a ductile slip-load curve and a very high slip capacity.
\end{abstract}

Keywords: demountable floor systems; novel shear connector; deconstruction

\section{Introduction}

Concrete and steel are the most widely used construction materials, the production of those generates high levels of carbon dioxide; yet the demand for their use is continuously increasing. By reusing the construction materials not only the carbon dioxide reduces but also the amount of construction waste that goes to landfill. High sustainability standards can be achieved by developing demountable structural systems offering the advantages of deconstruction and reuse of materials and structural components. However, the 'Design for Deconstruction' concept cannot be applied on beams as currently constructed, since the headed studs are welded in the top flange of the steel section. Recent research efforts propose different types of demountable shear connectors.
Modified threaded studs bolted on the beam's top flange were proposed and tested in push out tests by Lam and Saveri [1] and Dai et al. [2] and numerical models were developed. The results showed that the demountable shear connectors have comparable strength and lower initial stiffness compared to headed studs. Pavlovic at al. [3] performed four push out tests and advanced numerical simulations on single nutted high strength bolts embedded in prefabricated concrete slabs. They found similar strength, half initial stiffness and limited ductility for the demountable connector compared to a similar stud. Moynihan and Allwood [4] performed three beam tests using M20 bolted shear connectors and in situ slabs, formed in a profile steel sheet. They found a similar mode of failure between the demountable 
shear connectors and the welded ones published elsewhere. High strength friction bolts were proposed and tested in combination with geopolymer precast slabs firstly in push out tests by Liu et al. [5] and later in beam tests by Ataei et al. [6]. The push out tests showed rigid initial behaviour followed a sudden large slip once the friction was overcome and subsequent bolt fracture. The beam tests showed satisfactory strength and ductility. Two types of blind bolts were tested in push out and beam tests by Pathirana et al. [7] and numerical models were developed. The results showed that the blind bolts could be used as an alternative to welded studs.

This paper presents a novel demountable shear connector offering the following unique features: 1) it facilitates the deconstruction procedure since it is not fully embedded and thus the operations can be implemented from the top of the floor; 2) the unique shape of the connector promotes a ductile and predictable slip-load behaviour; and 3 ) it has adjustable strength and stiffness dependent on the selected geometry and a very high slip capacity. The structural behavior of the proposed system was investigated by ten horizontal push out tests. Theoretical predictions are proposed based on plastic beam analysis.

\section{Steel concrete composite beams with hollow core slabs and a demountable steel yielding shear connector}

\subsection{Description of the proposed system}

The proposed steel concrete composite floor system utilizes precast $\mathrm{HCUs}$ and a novel demountable steel-yielding mechanism, denoted as yielding pocket (YP). Fig. 1 shows a $3 \mathrm{~d}$ view of a part of a steel section including two HCUs, one YP installed and three open cores per HCU. The HCUs have one or two edge cut outs, depending on the degree of shear connection required, made through the depth of the HCUs at the edges parallel to the steel section axis, in order to accommodate the installation of the YPs. The YP consists of a steel square hollow section having a steel plate welded at the bottom and total length equal to the slab depth. Vertical elongated holes are cut on the sides of the YP that are parallel to the beam axis in order to form vertical steel strips. Aligned horizontally slotted holes are also opened on the same sides of the YP.

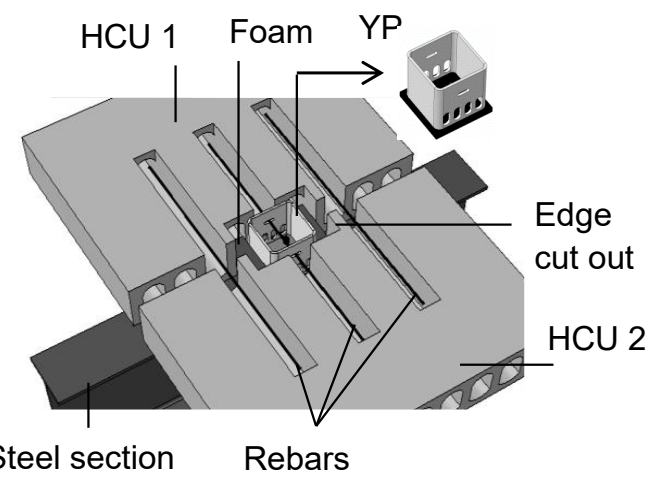

Fig. 1. $3 \mathrm{~d}$ view of the proposed connection

Fig. 1 shows a $3 \mathrm{~d}$ view of the YP. Four high strength bolts are used to clamp the YP on the top flange of the steel section, as shown in Fig.1. Rebars are placed in the open cores. A rebar is inserted through the horizontally slotted hole of the YP and placed in the middle open core, aiming to prevent uplift of the slab during the bending of the beam. A 50- mm gap is left between the YP and the HCUs, and in situ concrete is poured to fill the open cores and the gaps around the YP. Before pouring the in situ concrete polythene foam is used as formwork around the YP to disconnect the bottom part of the concrete from the YP. The expected deformed shape of the YP under the longitudinal bending of the beam is shown in Fig. 2. Therefore, a ductile yielding failure of the $\mathrm{YP}$ is promoted instead of a brittle shear failure of the bolts that would occur if the concrete was in fulldepth contact with the YP. The construction of the proposed system consists of the following steps: a) The HCUs are placed on the steel section; b) The YPs with the middle rebar passing through the slotted holes are fixed on the top flange of the steel sections using high strength bolts; c) Polythene foam is placed around the YPs and the rest of the rebars are placed in the open cores of the HCUs and; d) In situ concrete is poured to cover the open cores and the gaps between the YPs and the HCUs. 


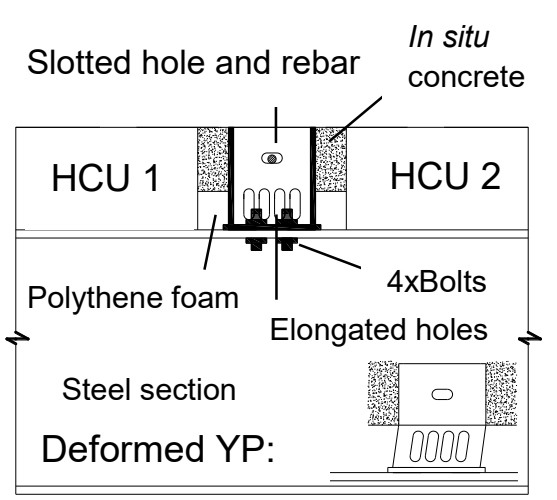

Fig. 2. Section of the proposed connection

The deconstruction consists of the following steps: a) the concrete 'tooth' around the YP shown in Fig. 2 is removed using a standard concrete cutting tool; b) the rebar passing through the YP is cut; c) the YPs are unbolted and removed and; d) the slabs are removed and all the steel structural components can be reused directly in a new building. Additionally the HCUs may be reused by removing the concrete strip above the steel section and cutting all the rebars in the middle. The rebars will protrude out of the concrete slab and couplers may be fitted to them to connect adjacent HCUs in a new building without re-opening the cores.

\subsection{Mechanics of the proposed system}

Fig. 3 shows the geometric properties of of the YP. The YP is deformed under the longitudinal shear force in a composite beam, as shown in Fig. 4. The foam around the YP is placed such as the bottom fibres of the concrete tooth are in line with the top ends of the vertical strips. The shear resistance is provided by the bending of the vertical strips and walls including the corners of YP. Assuming fixed boundary conditions, the vertical strips are expected to develop two plastic hinges at their ends, shown in Fig. 4.

The plastic moment resistance of a vertical strip is given by:

$$
M_{p, s t i p}=f_{y} \cdot \frac{t \cdot w^{2}}{4}
$$

, where $\mathrm{f}_{\mathrm{y}}$ is the yield strength of the vertical strip material. The strength provided by all the vertical strips is given by:

$$
F_{p, s t i p s}=2 \cdot \frac{M_{p, s t r i p}}{h_{1}} \cdot n
$$

, where $\mathrm{n}$ is the total number of vertical strips.

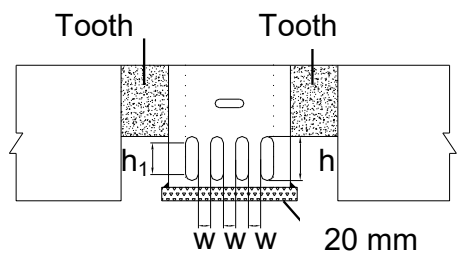

Fig. 3. Geometric properties of YP

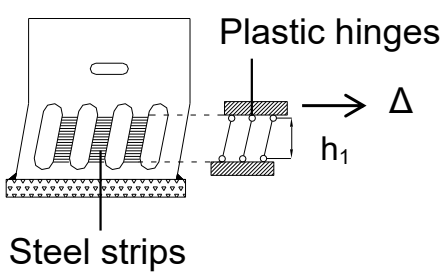

Fig. 4. Yielding mechanism of YP

The plastic moment resistance of one transverse vertical wall, $M_{p \text {,wall, }}$ is calculated using plastic analysis of the section taking into account the corners of the YP. It is given by:

$M_{p, \text { wall }}=Z_{p} \cdot f_{y w}$

, where $Z_{\mathrm{p}}$ is the plastic section modulus and $\mathrm{f}_{\mathrm{yw}}$ is the yield strength of the vertical walls material. The strength provided by the two vertical walls is given by:

$$
F_{p, \text { walls }}=2 \cdot \frac{2 \cdot M_{p, \text { wall }}}{h}
$$

The total strength of the YP is given by:

$$
F_{p}=F_{p, \text { strips }}+F_{p \text {,walls }}
$$

Capacity design rules are applied to ensure that the bolts and the steel plate remain elastic. Considering that the force is dispersed into the concrete component, potential failure modes include ripping, splitting and shear cracking [8]. Since shear cracking is the most critical of those for the specific geometry of specimens, the shear strength in $\mathrm{kN}$ may be estimated by the shear friction model proposed in [9]:

$$
F_{\text {con }}=c \cdot f_{t} \cdot A_{c}+\mu \cdot A_{s} \cdot f_{y} \cdot k
$$


where $f_{t}$ is the mimimum concrete tensile strength between the HCU and the in situ concrete, $A_{c}$ is the area of the shear plane, $A_{s}$ is the area of the reinforecement, $f_{y}$ is the yield stress of the rebars, $\mathrm{k}$ is a reduction factor to account for reduced anchorage taken as 0.5 and recommended by [10] and c and $\mu$ are cohesion and friction coefficients taken equal to 0.5 and 0.9 respectively by inspection of the values given in [9].

\section{Horizontal push out tests}

\subsection{Push out specimens}

Figs. 5 and 6 show a plan view and a longitudinal section of a typical push out specimen. Two HCUs were attached to a UB $533 \times 210 \times 92$ steel section using one YP for each specimen. The HCUs were standard units of 9 cores, $1200 \mathrm{~mm}$ nominal width, $200 \mathrm{~mm}$ depth and $800 \mathrm{~mm}$ length. Five cores were opened to serve the placement of transverse reinforcement. The length of the edge cut out in the direction parallel to the steel section axis was $300 \mathrm{~mm}$ and the width $70 \mathrm{~mm}$. Before pouring the in situ concrete foam was placed in proper positions around the YP. The core placed immediately before the YP (it is the 4rth core showing in Fig. 5 counting from left to right) was fully filled with in situ concrete to avoid failure of the concrete slab, as it was proved by tests. The YPs were manufactured from steel hollow section of SHS180x10 and SHS180x8 tubes of $\mathrm{S} 355 \mathrm{~J} 2 \mathrm{H}$ steel grade. The steel plate welded at the bottom of YP was of 200x200 $\mathrm{mm}$ length and $20 \mathrm{~mm}$ thickness, made of S275 steel grade. The rebars placed were of $12 \mathrm{~mm}$ diameter and S500 steel grade. The parameters varied in tests were the YP geometry and the concrete strength. Table 1 shows the geometric characteristics of the YP and the predicted strengths for the YP and the concrete using equations Eq.(5) and Eq. (6) in $\mathrm{kN}$. The concrete strength $\mathrm{F}_{\text {con }}$ in Table 1 is multiplied by 2 to take into account approximately the strength of the slab at both right and left side of YP. Since the strength of the YP approaches the strength of the concrete in a percentage around $100 \%$ for the specimens SP5 and SP6, shear cracking is likely to occur. The number following the prefix 'SP' indicates the YP geometry group; thus six different YP geometries were tested.
Table 2 presents the material properties of the in situ concrete at the testing day. A number of cubes and cylinders were casted and cured along the push out specimens to obtain the compressive and splitting strength of the in situ concrete. Table 2 gives the average compressive strength of three cubes and the average splitting strength of two cylinders. Tensile coupon tests were cut from the flat and the corner regions of the SHS180x180x10 and SHS180x180x8 tubes to obtain the material properties. The properties are the modulus of Elasticity, the $0.2 \%$ proof stress, the ultimate stress and the tensile strain related to the ultimate stress. Table 3 shows the average properties obtained from three coupon tests.

Table 1.Geometric properties of YP and strength predictions

\begin{tabular}{cccccc}
\hline Spec. & $\begin{array}{c}\mathbf{t} \\
(\mathbf{m m})\end{array}$ & $\begin{array}{c}\mathbf{w} \\
(\mathbf{m m})\end{array}$ & $\begin{array}{c}\mathbf{h} \\
(\mathbf{m m})\end{array}$ & $\begin{array}{c}\mathbf{F}_{\mathbf{Y P}} \\
\mathbf{( k N )}\end{array}$ & $\begin{array}{c}\mathbf{2} \cdot \mathbf{F}_{\mathbf{c o n}} \\
\mathbf{( k N )}\end{array}$ \\
\hline SP1A & 8 & 17 & 75 & 150 & 490 \\
SP1B & 8 & 17 & 75 & 150 & 420 \\
SP1C & 8 & 17 & 75 & 150 & 420 \\
SP2A & 8 & 13 & 55 & 186 & 420 \\
SP2B & 8 & 13 & 55 & 186 & 482 \\
SP3 & 8 & 17 & 55 & 215 & 380 \\
SP4A & 10 & 14 & 75 & 263 & 490 \\
SP4B & 10 & 14 & 75 & 263 & 410 \\
SP5 & 10 & 18 & 65 & 345 & 344 \\
SP6 & 10 & 14 & 65 & 310 & 326 \\
\hline
\end{tabular}

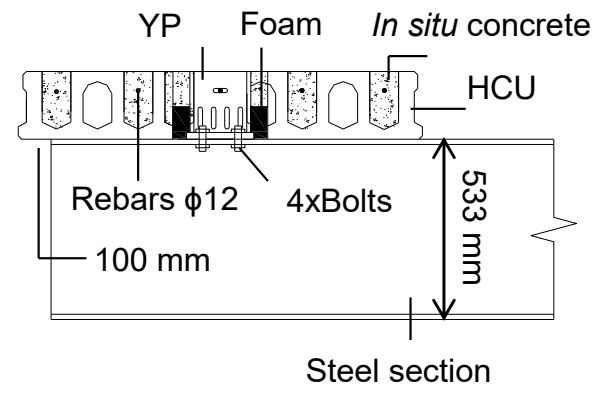

Fig. 5. Side view of specimen

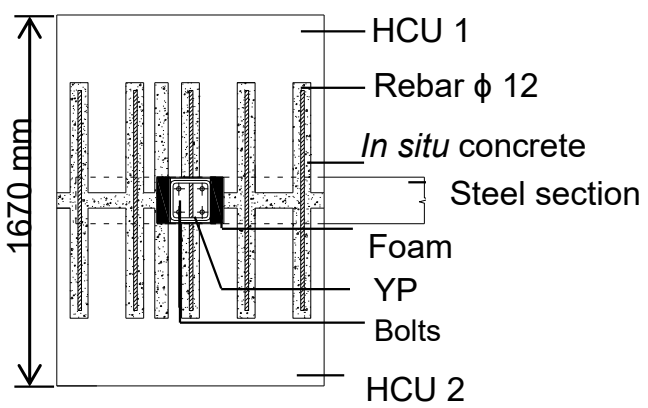

Fig. 6. Plan view of specimen 
Table 2. In situ concrete properties

\begin{tabular}{ccc}
\hline Spec. & $\begin{array}{c}\text { Compressive } \\
\text { strength } \\
\mathbf{f}_{\mathbf{c u}} \\
\mathbf{( M P a )}\end{array}$ & $\begin{array}{c}\text { Splitting } \\
\text { strength } \\
\mathbf{f}_{\mathbf{t}} \\
(\mathbf{M P a})\end{array}$ \\
\hline SP1A & 61 & 4.3 \\
SP1B & 52 & 2.9 \\
SP1C & 50 & 2.9 \\
SP2A & 47 & 2.9 \\
SP2B & 56 & 3.6 \\
SP3 & 38 & 2.5 \\
SP4A & 68 & 4.5 \\
SP4B & 47 & 2.8 \\
SP5 & 35 & 2.1 \\
SP6 & 30 & 1.9 \\
\hline
\end{tabular}

Table 3. Coupon test results

\begin{tabular}{|c|c|c|c|c|}
\hline Region & $\begin{array}{c}\text { Mod. } \\
\text { of } \\
\text { Elast. } \\
\text { (MPa) }\end{array}$ & $\begin{array}{l}0.2 \% \\
\text { proof } \\
\text { stress } \\
(\mathrm{MPa}) \\
\end{array}$ & $\begin{array}{c}\text { Ult. } \\
\text { stress } \\
(\mathrm{MPa})\end{array}$ & $\begin{array}{l}\begin{array}{l}\text { Strain at } \\
\text { ult.stress }\end{array} \\
\text { (MPa) }\end{array}$ \\
\hline $\begin{array}{c}\text { Flat } \\
180 \times 8 \\
\text { Corner }\end{array}$ & 193600 & 390 & 460 & 0.168 \\
\hline $\begin{array}{c}\text { 180x8 } \\
\text { Flat }\end{array}$ & 221000 & 390 & 425 & 0.02 \\
\hline $\begin{array}{l}180 \times 10 \\
\text { Corner } \\
180 \times 10\end{array}$ & 202850 & 500 & 565 & 0.087 \\
\hline
\end{tabular}

\subsection{Test set up and loading procedure}

Ten horizontal push out tests were performed using the test set up shown in Fig.7. An hydraulic actuator of $1000 \mathrm{kN}$ force capacity was used to push the HCUs against the steel section through the spreader beam. The tests were performed by employing two configurations to transfer the load from the actuator to the spreader beam. The first one included the use of high density wooden parts fitted to the gap between the HCU and the spreader beam. The second one included the construction of a mortar tooth between the HCUs and the flange of the spreader beam. The specimens SP1A and SP6 were tested employing the second configuration. Two linear variable differential transformers (LVDTs) were used to measure the relative slip between the slabs and the steel section. Two additional LVDTs were used to measure the uplift for the specimens SP1A and SP6. The LVDTs were placed closely to the YP; one on each side of the specimen.
Force control load was initially applied up to $40 \%$ of the expected failure load and then cycled 25 times between $5-40 \%$ of the expected failure load. After the cyclic loading, displacement control load was applied up to failure.

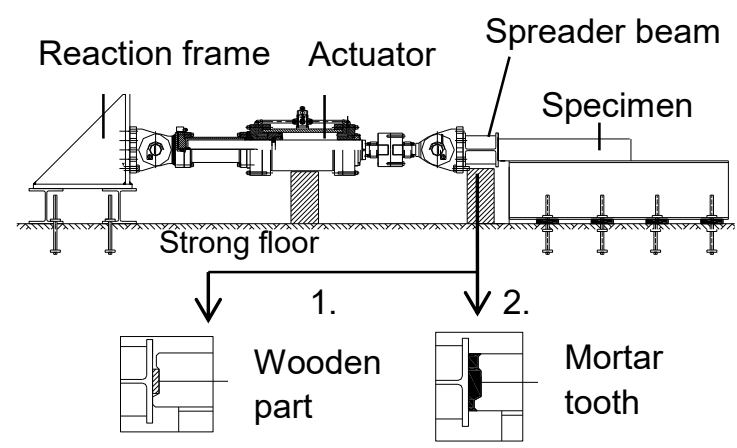

Fig. 7. Side view of the test set up

\section{Test results}

\subsection{Failure modes}

Table 4 summarizes the yield and the maximum force experimentally obtained, the relative slip at the maximum force and the failure modes observed during the experiments. The specimens SP1 to SP4 which were designed to have low to medium YP strength and high concrete strength failed in a ductile mode showing concentration of plastic deformations in the YP. The specimen SP5 designed to have high strength YP and low concrete strength failed in shear concrete cracking showing very little deformation in the YP. The specimen SP6 failed in a mixed mode.

The specimen SP1A was brought up to ultimate failure aiming at identifying all the potential failure modes. The behaviour of the specimen was ductile up to $350 \mathrm{kN}$ and corresponding relative slip of $45 \mathrm{~mm}$. No cracks were visible on the top surface of the slabs up to this point. After reaching the relative slip of $45 \mathrm{~mm}$, the first row of bolts in the direction of the load, started bearing on the YP's vertical wall, which resulted in a sudden increase of the load up to $500 \mathrm{kN}$. By further increase of the imposed displacement, the slabs of the specimen started sliding over the YP and introduced secondary hogging moments to the slabs. Those secondary bending moments finally caused failure of the slab manifested by a sudden formation of a crack running across 
the width of the slab. Although the ultimate failure was due to concrete, the responce of specimen was ductile since relative slips less than $18 \mathrm{~mm}$ was recorded in previously performed full scale beam tests in [11]. Fig. 8 shows the deformed shape of YP and the bolts' bearing on the YP's vertical wall, up to a very high slip of $45 \mathrm{~mm}$. Fig. 9 shows the ultimate failure of the slab.

Table 4. Failure modes

\begin{tabular}{ccccc}
\hline Specimens & $\begin{array}{c}\text { Yield } \\
\text { force } \\
\mathbf{F y}_{\mathbf{y}, \mathbf{e x p}} \\
\mathbf{( k N )}\end{array}$ & $\begin{array}{c}\text { Max } \\
\text { force } \\
\mathbf{F}_{\mathbf{m a x}, \mathbf{e x p}} \\
\mathbf{( k N )}\end{array}$ & $\begin{array}{c}\text { Slip } \\
\text { at } \\
\text { max. } \\
\text { force } \\
\text { (mm) }\end{array}$ & $\begin{array}{c}\text { Failure } \\
\text { modes }\end{array}$ \\
\hline SP1A & 170 & 352 & 46 & Ductile \\
SP1B & 170 & 325 & 35 & Ductile \\
SP1C & 160 & 250 & 30 & Ductile \\
SP2A & 200 & 356 & 35 & Ductile \\
SP2B & 200 & 335 & 33 & Ductile \\
SP3 & 230 & 359 & 36 & Ductile \\
SP4A & 260 & 376 & 33 & Ductile \\
SP4B & 260 & 377 & 32 & Ductile \\
SP5 & NA & 322 & 9 & Conc. \\
failure \\
SP6 & 320 & 425 & 24 & Mixed \\
\hline
\end{tabular}

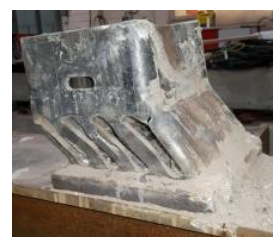

a)

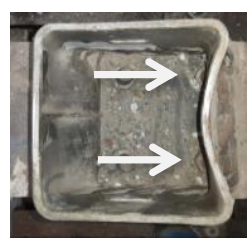

b)
Fig. 8. Deformed shape of YP of SP1A and bolts' bearing on wall

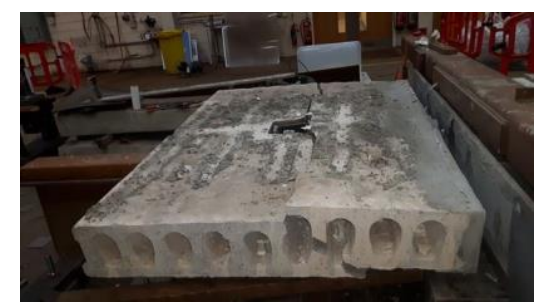

Fig. 9. Failure of slab of SP1A

The specimen SP5 failed due to concrete cracking, as shown in Fig. 10. Two transverse cracks were formed prematurely on the top surface of the slabs of the specimen. Shear (diagonal) cracks developed in the surface of the slabs when the load reached $314 \mathrm{kN}$. The cracks became wider with further increase of the force and the slab ultimately failed in extensive shear cracking at $320 \mathrm{kN}$ and corresponding relative slip $8.5 \mathrm{~mm}$, followed by sudden drop in the load at $286 \mathrm{kN}$, where the test was stopped. The shear cracks were seen in one side of the specimen due to in plane eccentricities introduced to the specimen during the application of the loading. The formation of the transverse cracks was unexpected and was attributed to the introduction of within the depth of the slab eccentricities resulted by imperfections during the application of the loading. Very little deformation was additionally observed in YP after dismantling the specimen.

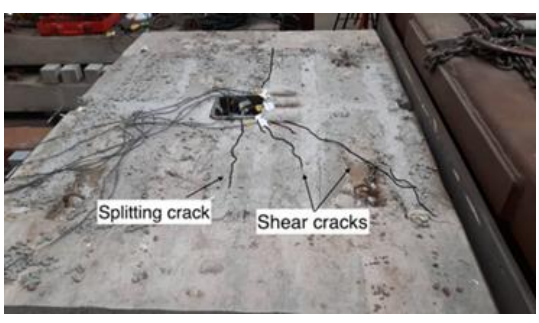

Fig. 10. Cracking pattern of slab of SP5

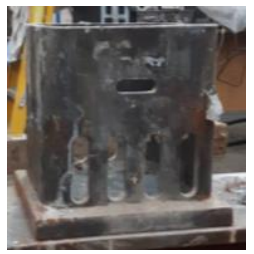

Fig. 11. Deformed shape of YP of SP5

The response of specimen SP6 was ductile up to $427 \mathrm{kN}$ and corresponding relative slip $19.5 \mathrm{~mm}$. After reaching 19.5 $\mathrm{mm}$ of relative slip, diagonal cracks started to become visible on the surface of the slab. The shear cracks continued propagating, resulting in reduction of the force by $4 \mathrm{kN}$. Fig. 12 shows the ultimate failure of the slab at the end of the test at $423 \mathrm{kN}$ and corresponding relative slip $23.7 \mathrm{~mm}$. Fig. 13 shows the bending of the YP. Eq. (6) could predict the shear concrete cracking of the specimens SP5 and SP6.

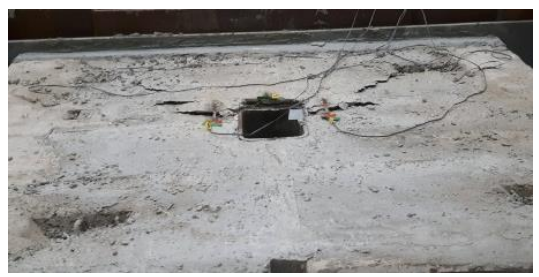

Fig. 12. Shear cracking of slab of specimen SP6 


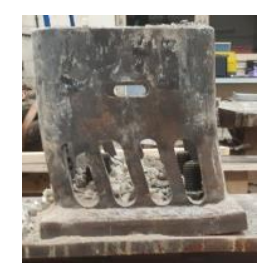

Fig. 13. Deformed shape of YP of SP6

The specimen SP1C excibited out of bending deformation and the full plastic force derived from equation Eq. (5) did not develop. This specimen was constructed having insufficient amount of concrete around the corners of YP which otherwise provide proper boundary conditions and avoids the 'opening' of the yielding device.

\subsection{Force-slip behavior}

The force-slip curves are shown in Figs. 14-16. Fig. 14 shows the curves of the group SP1. The sudden increase of the load from $350 \mathrm{kN}$ to $500 \mathrm{kN}$, indicates the bearing of the YP's wall on the first row of the bolts, as described previously. The slab failed at 500 $\mathrm{kN}$ and corresponding relative slip $50 \mathrm{~mm}$ followed by a softening behavior up to $60 \mathrm{~mm}$ of slip, where the test was stopped. The specimen SP1C exhibited out of bending deformation resulting in reduced strength compared to the one of specimens SP1A and SP1B.

Fig. 15 shows the force-slip curves of the groups SP2 and SP4 and of specimen SP3, which showed a ductile mode of failure. The tests were intentionally stopped around $30-35 \mathrm{~mm}$ because no visible damage on the surface of the slabs was observed up to that point and to test the concept of deconstruction and reusability. All the steel structural components were reusable and the slabs of the specimen SP2A were additional reused successfully without affecting the structural behavior. Eq. (5) can predict the yield strength of the YP with good accuracy, as shown in Tables 2 and 4.

The force-slip behaviour of a composite connection including headed studs in conjunction with HCUs [12] is superimposed to the previously obtained experimental curves shown in Fig.15.

Fig. 17 shows the force-slip curves of the specimens SP5 and SP6. The specimen SP5 was designed to have the highest strength; however the specimen SP6 showed higher strength and stiffness. This is attributed to the early concrete failure of the specimen SP5. Still, the maximum slip achieved in this test, which is the lowest between all the specimens tested, is higher than the one required by Eurocode 4 [13].

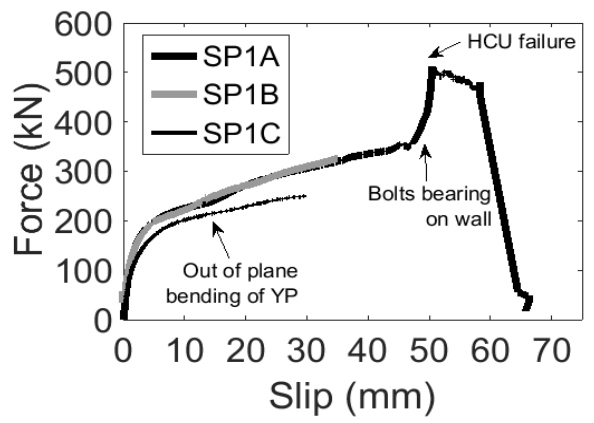

Fig. 14. Force-slip curves of group SP1

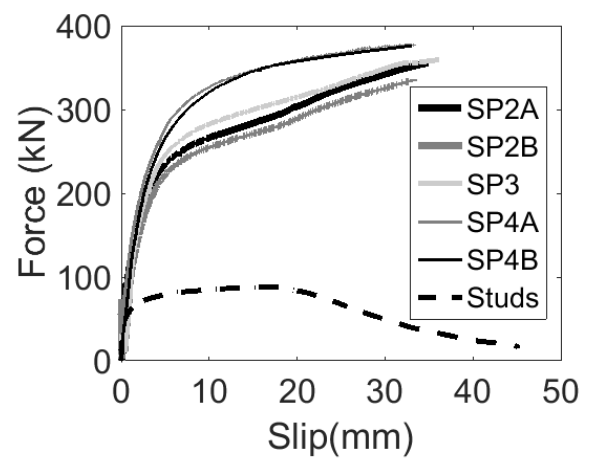

Fig. 15. Force-slip curves of groups SP2 to SP4

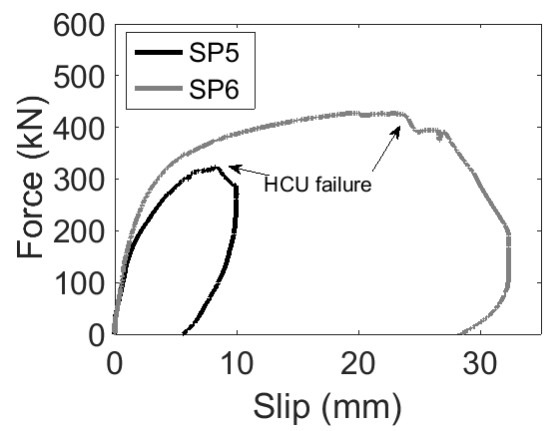

Fig. 16. Force-slip curves of SP5 and SP6

\subsection{Uplift results}

The development of uplift was taken from the recordings of the two LVDTs during the tests SP1A and SP6. The uplift [13] should be limited so as to be equal to half of the longitudinal relative slip when the shear connectors are subjected to $80 \%$ of their ultimate load. The uplift is acceptable for both specimens and equal to $1.98 \mathrm{~mm}$ 
and $2.48 \mathrm{~mm}$ at $80 \%$ of the ultimate load for the specimens SP1A and SP6 respectively.

\section{Conclusions}

A novel demountable shear connector is proposed for use in steel concrete composite beams in conjunction with hollow core units. Ten horizontal push out tests performed to investigate the structural behavior of the proposed system. The strength of the connection was predicted by using simple mechanics based on plastic beam analysis and aggregate interlock mechanism for the concrete. The following conclusions are drawn:

1.The experimental results show that the proposed shear connector has high initial stiffness and increased strength as compared to a welded shear stud.

2. The proposed shear connector achieved a slip capacity between $9 \mathrm{~mm}$ and $46 \mathrm{~mm}$; much higher than the minimum slip required by Eurocode 4 .

3. The strength of the connection can be predicted using equations based on plastic beam analysis and can be adjusted to the geometric characteristics of the shear connector. The full plastic strength of the connector can be achieved provided that shear cracking of the slab at the critical shear planes is prevented.

4. The concept of deconstruction and reuse was experimentally assessed by reusing the undamaged steel and slabs in a new test without affecting the structural behavior.

\section{References}

[1] Lam D, Saveri E. Shear Capacity of Demountable Shear Connectors. Proceedings of the 10th International Conference on Advances in Steel Concrete Composite and Hybrid Structures 2012;767774

[2] Dai XH, Lam D, Saveri E. Effect of concrete strength and stud collar size to shear capacity of demountable shear connectors. Journal of Structural Engineering 2015; 141(11): 42904015025.

[3] Pavlovic M, Markovic Z, Veljkovic M, Budevac D. Bolted shear connectors vs. headed studs behaviour in push out tests. Journal of Constructional steel Research 2013; 88:134-149

[4] Moynihan M, Allwood JM. Viability and performance of demountable composite connectors. Journal of Constructional Steel Research 2014; 99: 47-56

[5] Liu X, Bradford MA, Lee SSM. Behavior of high strength friction grip bolted shear connectors in sustainable composite beams. Journal of Structural Engineer 2014;141(6): 04014149

[6] Ataei A, Bradford MA, Liu X. Experimental study of composite beams having a precast geopolymer concrete slab and deconstructable bolted shear connectors. Journal of Engineering Structures 2016; 114: 1-13

[7] Pathirana ISW, Uy B, Mirza O, Zhu X. Flexural behaviour of composite steelconcrete beams utilizing blind bolt shear connectors. Journal of Engineering Structures 2016; 114:181-194.

[8] Oehers DJ, Bradford MA. Composite steel and composite structural members: Fundamental behaviour, Elsevier Science Ltd, Oxford, UK; 1995

[9] EN 1992-1-1 - Eurocode 2 - Design of concrete structures - Part 1-1: General rules and rules for buildings, European Committee for Standardization, 2004,p.92-93

[10] Model Code 2010. First complete draft vol. 1. Comité Euro-International du Béton, Secretariat permanent, Case Postale 88, CH1015 Lausanne, Switzerland; 2010

[11] Vasdravellis G, Uy B, Tan EL, Kirkland B. Behaviour and design of composite beams subjected to sagging bending and axial compression. Journal of Constructional Steel Researsch 2005; 110:29-39

[12] Lam D, Elliott KS, Nethercot DA. Push-off tests on shear studs with hollow-cored floor slabs. The Structural Engineer 1998; 76 (9): 167-174

[13] Eurocode 4: Design of composite steel and concrete structures. Part 1-1: General rules and rules for buildings. EN 1994-1-1;2010 